https://doi.org/10.46344/JBINO.2020.v09i04.24

\title{
SUGGESTING THE ENHANCED PRODUCTION OF MUNGBEAN IN FUTURE TO ASSURE NUTRITIVE FOOD SUPPLY TO POOR POPULATION IN SITUATIONS SIMILAR TO COVID-19 LOCKDOWN IN DEVELOPING COUNTRIES
}

\author{
Nirmala Sehrawat* \& Mukesh Yadav \\ Department of Biotechnology, Maharishi Markandeshwar (Deemed to be University), Mullana 133207, Ambala, Haryana, India
}

Email: nirmalasehrawat@gmail.com

(Received on Date: $30^{\text {th }}$ May 2020 Date of Acceptance: 14 ${ }^{\text {th }}$ June 2020 Date of Publish: $01^{\text {st }}$ July 2020)

\begin{abstract}
COVID-19 has affected the whole world adversely. It is severely affecting the economic status of the various countries. The spread of novel corona virus and subsequent long term lock down through developing countries give rise to issue related to food safety and security. This requires sufficient availability of nutritious food to feed their peoples. Regular distribution and consumption of the food may lead to shortage or end of the food supply in long term. Mostly the poor peoples, workers residing in slums, rural areas or poor villages could not get proper food supply to calm their hunger. Improper food supply and lack of nutritious diet among these people contributes towards malnutrition problem and death rate. To combat these situations, there is a need to produce more food crops with high nutritional value as mungbean in future. Higher production of mungbean in future may be one of the solutions to tackle with such situations where nutritive diet supply becomes a challenge.
\end{abstract}

Keywords: mungbean, enhanced production, nutrition, lockdown, COVID-19, food security

No: of References: 10 


\section{Higher production of Mungbean and assuring nutritive food supply in future}

Mung bean (Vigna radiata L.) is an important edible traditional legume crop consumed as a nutritional and healthy ingredient worldwide. It has an excellent source of easily digestive proteins for the vegetarians at low cost (García et al. 2013; Nair et al. 2013). Mungbean seed constitutes balanced nutrients including essential amino acids, fatty acids, fibers, minerals and vitamins (Gupta et al. 2018). Mungbean have clinical and pharmacological significance due to presence of significant amount of bioactive compounds in various parts of mungbean particularly, seed (raw, boiled, or fermented seeds) and seed coat having health promoting effects (Yi-Shen et al. 2018; Hou et al. 2019).

Mungbean is a fast growing, warm season annual crop with short life span (7590 days) and low input requirements (Dahiya et al. 2015). Symbiotic association of its root and Rhizobium helps in nitrogen fixation which improves soil fertility. Short life duration and low input requirements makes this an ideal crop for major agricultural cropping system as cash, catch or intercrop (Allito et al. 2015). Cultivation of this crop by marginal farmers also improves their economic and health status. This also provides employment to the women workers. Besides nutritional, pharmacological, agricultural and economic importance of this valuable crop, its production is still stagnant as compared to the cereal food crops. This may be either due to i) susceptibility of mungbean towards climate changes and environmental stress factors, or ii) lack of awareness in farmers, unemployed poor peoples and non-scientific community about its important characteristics (Singh 2018). So there is a need to organize various agriculture extension programs in villages and rural areas which have no any connection with the outside advancements in urban sectors. So, people should be learned necessary technique and method to produce mungbean by using limited natural resources.

Enhanced production and storage of mungbean by the poor farmers helps them to take healthy diet in drastic circumstances as lockdown period worldwide. Therefore, the farmers, researchers, breeders and women should be encouraged for more production of mungbean in current scenario. These practices may ensure sufficient availability of nutritious food as healthy diet for everyone in near future in case of any pandemic occurrence. Distribution of dry seeds of mungbean door to door is also an easy, less tedious and laborious way as compared to the delivery of packed food products. Mungbean dry seeds don't encounter any damage during transportation to a long distance. Hence, production, storage, distribution and consumption of mungbean may be a costeffective alternative for fresh food and vegetables to overcome food security issue in future adverse conditions. Vegetarians and non-vegetarians, all should include mungbean as a functional food in their diet pattern for better health 
status (Nair et al. 2013; Foyer et al. 2016; Xie et al. 2019).

Various countries are facing lockdown conditions due to COVID-19. The disease has spread rapidly throughout the world. Poor peoples are among the most affected domain due to the disease. Poor peoples have lost their jobs. They are not able to take fresh fruits and vegetables in their diet which may lead to compromised health. Developing countries are facing problems in providing nutritive food to such poor peoples. Mungbean may be one of the solutions to provide nutritive food to the needy peoples. Enhanced production of mungeban in future may ensure nutritive food security in situations similar to COVID19 lockdown.

\section{Conflict of interest:}

None to declare

\section{Acknowledgement}

Authors are thankful to Head, Department of Biotechnology, Maharishi Markandeshwar (Deemed to be University), Mullana-Ambala, India.

\section{References:}

Allito, B. B., Nana, E. M., \& Alemneh, A. A. (2014). Rhizobia strain and legume genome interaction effects on nitrogen fixation and yield of grain legume: a review. Molecular Soil Biology, 20, 1-6.

Dahiya, P. K., Linnemann, A. R., Van Boekel, M. A. J. S., Khetarpaul, N., Grewal,
R. B., \& Nout, M. J. R. (2015). Mung bean: Technological and nutritional potential. Critical Reviews in Food Science and Nutrition, 55, 670-688.

Foyer, C. H., Lam, H.-M., Nguyen, H. T., Siddique, K. H. M., Varshney, R. K., Colmer, T. D., et al., (2016). Neglecting legumes has compromised human health and sustainable food production. Nature Plants, $2,16112$.

García, M. C., Puchalska, P., Esteve, C., \& Marina, M. L. (2013). Vegetable foods: a cheap source of proteins and peptides with antihypertensive, antioxidant, and other less occurrence bioactivities. Talanta, $106,328-349$.

Gupta, N., Srivastava, N., \& Bhagyawant, S. S. (2018). Vicilin-A major storage protein of mungbean exhibits antioxidative potential, antiproliferative effects and ace inhibitory activity. PLOS ONE, 13, e0191265.

Hou, D., Yousaf, L., Xue, Y., Hu, J., Wu, J., Hu, X., Feng, N., \& Shen, Q. (2019) Mung Bean (Vigna radiata L.): Bioactive polyphenols, polysaccharides, peptides, and health benefits. Nutrients, 11, 1238.

Nair, R. M., Yang, R.-Y., Easdown, W. J., Thavarajah, D., Thavaraja, P., Hughes, J.dA., \& Keatinge, J. (2013) Biofortification of mungbean (Vigna radiata) as a whole food to enhance human health. Journal of the Science of Food and Agriculture, 93: 1805-1813. 
Singh, G. (2018). Climate change and sustainable management of salinity in agriculture. Research in Medical \& Engineering Sciences, 6, RMES.000635.

Xie, J., Du, M., Shen, M., Wu, T. \& Lin, L. (2019). Physico-chemical properties, antioxidant activities and angiotensin-I converting enzyme inhibitory of protein hydrolysates from mung bean (Vigna radiate). Food Chem., 270: 243-250.

Yi-Shen, Z., Shuai, S. \& FitzGerald, R. (2018). Mung bean proteins and peptides: nutritional, functional and bioactive properties. Food \& Nutrition Research, 62, 1290

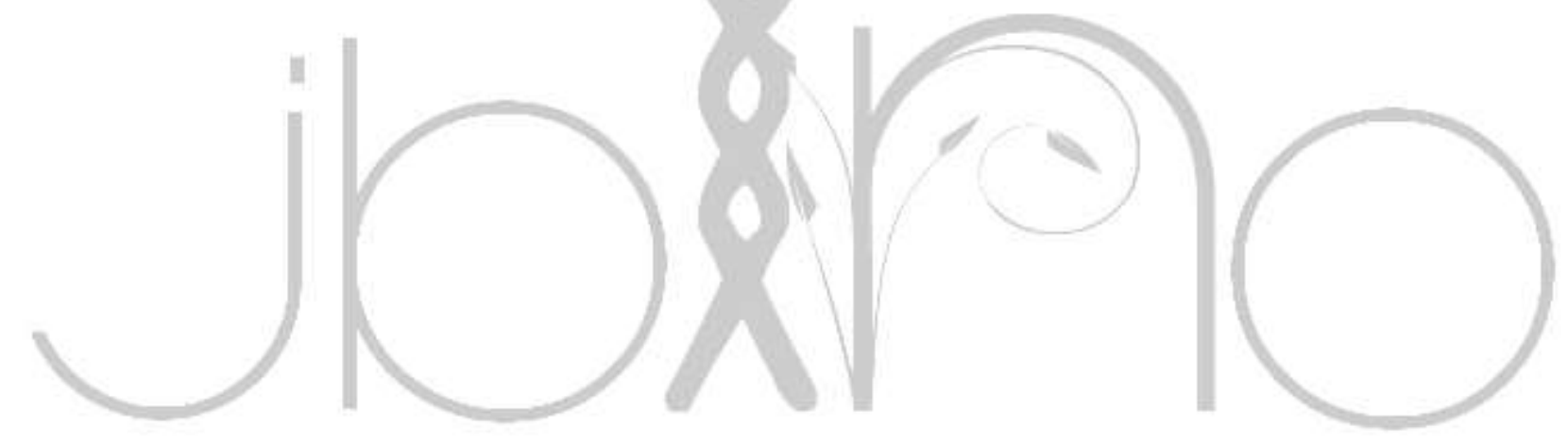

